\title{
Hegel y Deleuze: filosofias de la naturaleza
}

\author{
Julián Ferreyra \\ CONICET/Universidad de Buenos Aires
}

Resumen: Más allá de sus diferencias y tensiones conceptuales, Hegel y Deleuze comparten el esfuerzo por concebir una filosofia de la naturaleza que no se confunda con el conocimiento científico de sus épocas respectivas - con el cual sin embargo se relacionan. En este artículo, se toma como base el orden de exposición de la "física orgánica" en la Enciclopedia de las ciencias filosóficas de Hegel para ponerla en relación con tres capítulos de Mil Mesetas, de Deleuze y Guattari. Así la naturaleza geológica, la vegetal y la animal se confrontan respectivamente con "La geología de la moral", el rizoma y los devenires-animales. El resultado, desde el estudio de Deleuze, es la posibilidad de encontrar, dentro de la caótica exposición de Mil mesetas, una determinación ontológica progresiva y una valorización de las formas existentes. Desde la interpretación de Hegel se podrá encontrar, dentro de la rígida estructura de la escala de la naturaleza, la estimación de lo anómalo y singular.

Palabras clave: Deleuze; Hegel; filosofia de la naturaleza; escala de la naturaleza; devenir

\begin{abstract}
Hegel and Deleuze: philosophies of nature". Beyond their differences and conceptual tensions, Hegel and Deleuze share the effort to conceive a Philosophy of Nature that distinguishes itself from the scientific knowledge of their time - with which they nonetheless relate. This paper follows the order of exposition of the section "Organics" from Hegel's Encyclopedia of the Philosophical Sciences in order to relate it to three chapters of A Thousand Plateaus, by Deleuze and Guattari. Thus, the geological nature, the vegetal and the animal are each confronted to "the geology of morals", the rhizome and the animal-becoming. As a result, the supposed chaotic Deleuzian standpoint reaches a progressive ontological determination where the actual forms gain significance, while the rigid great chain of being that often conditions the Hegelian perspective makes room for the anomalous and the singular.
\end{abstract}

Keywords: Deleuze; Hegel; philosophy of nature; great chain of being; becoming 
Caro amigo, os aconsejo ante todo el Collegium Logicum. Alli se adiestrará bien vuestro espiritu, aprisionándolo en borceguies españoles,

a fin de que asi, más reflexivo, en adelante recorra con paso mesurado la vía del pensamiento, y no divague tal vez como un fuego fatuo de aqui para alli, a diestro y siniestro (...)

El que quiere conocer $y$ describir alguna cosa viviente, procura ante todo sacar de ella el espiritu; entonces tienen en su mano las partes; lo único que le falta, ;ay! es el lazo espiritual que las une. Naturae enchreiresin llama a eso la química, que, sin saberlo, se burla asi de sí misma. Goethe, Fausto ${ }^{1}$

"Se aprisionará a vuestro espíritu en borceguíes españoles, a fin de que no divague de aquí para allí, a diestro y siniestro", aconseja Mefistófeles al estudiante en el pasaje del Fausto que recoge el epígrafe. Pese a parecer razonable, es en realidad un consejo sádico, ya que los borceguíes españoles son un instrumento de tortura medieval2: inmovilizan el pie, lo hacen sufrir, no permiten el desplazamiento; en el límite, lo destruyen. En el submundo medieval la cuestión es bastante directa: con solo quitárnoslos, con solo poder quitárnoslos todo irá mejor (lo cual no quiere decir que sea fácil, que sea posible, que dependa de nosotros). Pero Goethe las introduce en un contexto espiritual: la "lógica" permite enderezar al pensamiento y hacerlo científico. Impide asî que se interne en el fuego fatuo de las cuestiones metafisicas. Los borceguíes españoles lógico-científicos limpiarian al pensamiento de las impurezas y anomalias especulativas que habitualmente arrastra y le son ajenos. Pero, al hacerlo, lo inmovilizan, lo hacen sufrir, lo torturan, lo violentan, lo traicionan; en el límite, lo destruyen.

1 Goethe, J.W., Fausto, Roviralta Borrell, J. (trad.), Buenos Aires: Losada, 2005, p. 49 (sección "Gabinete de estudio").

2 Spanische Stiefeln, también conocidos como "botas malayas". 
En realidad, los borceguíes españoles de la lógica y la ciencia reprimen el espíritu. No nos permiten captar el "lazo espiritual" que salva a la realidad de reducirse a meros fragmentos, aislados y sin sentido. Eso es lo que parece tener en mente Goethe al poner este ladino consejo en boca de Mefistófeles, y en ese sentido lo convoca Hegel cuando recurre a él en dos ocasiones en su Enciclopedia de las ciencias filosóficas ${ }^{3}$. El consejo de Mefistófeles debe ser invertido y en lugar de internarse en el Collegium Logicum, el estudiante debe leer entre líneas y evitarlo a toda costa.

Desde esta perspectiva, no es la metafísica, sino la lógica, la ciencia y el empirismo, ligadas hábilmente por la pluma de Goethe, las que deberian ser dejadas de lado, extirpadas del pensamiento filosófico cual funestos borceguíes españoles. Su presencia persistente en los textos filosóficos es la anomalía, la impureza, que debería ser quirúrgicamente extirpada. La filosofia volaría libre sin ellas.

Pero la cuestión dista de ser tan sencilla. No se trata de dejarse adiestrar ciegamente por la lógica, pero tampoco de errar de aquí para allí, a diestro y siniestro. La filosofia es el arte de pensar y no es posible pensar sin algo que nos fuerce (lo ajeno, lo violento ${ }^{4}$ ). Lo extraño limita y restringe al pensamiento, pero al mismo tiempo lo hace posible. Ni la lógica ni el empirismo son la excepción. Son una fuerza extraña que se aloja necesariamente en el seno del pensamiento filosófico. El tema es determinar cuál es el lugar, no necesariamente positivo, de estos extraños borceguíes españoles.

En estas páginas estudiaremos el problema en dos autores que, pese a las reservas que la ciencia de su época les ha generado, se han dejado interpelar por ella y por lo tanto le dieron un espacio significativo a lo largo de su obra: G.W.F. Hegel (Alemania, 1770-1831) y Gilles Deleuze (Francia, 1925-1995). Ambos han luchado por recuperar un lazo espiritual que no fuera mero naturae encheiresin ${ }^{5}$,

\footnotetext{
3 Hegel cita el pasaje mencionado del Fausto en su análisis de la "posición empirista respecto a la objetividad" de la Enciclopedia de las ciencias filosóficas y en la Introducción a la "Filosofia de la Naturaleza". Cf. Hegel, G.W.F., Enzyklopädie der philosophischen Wissenschaften im Grundrisse, en: Moldenhauer, E. y K. Michel (eds.), Werke en in zwanzig Bänden, v. VIII, Fráncfort d.M: Suhrkamp, 1970f., p. 110; ibid., v. IX, p. 21. Para el texto publicado por Hegel, utilizamos Hegel, G.W.F., Enciclopedia de las ciencias filosóficas, Valls Plana, R. (trad.), Madrid: Alianza Editorial, 1997 (colocamos la paginación de esta edición entre corchetes). Para los agregados, la traducción es mía.

4 "El pensamiento no piensa más que obligado y forzado" (Deleuze, G., Différence et répétition, París: PUF, 1968, p. 353). "Lo primero en el pensamiento es la fractura, la violencia" (ibid., p. 181). 5 "Naturae encheiresin es un término técnico en alquimia relacionado con la manera en que supuestamente el espíritu une el alma y el cuerpo. Los alquimistas esperaban encontrar un análogo a tal fuerza en la naturaleza y usarla para producir la 'piedra filosofal'. Mefistófeles se burla aquí
} 
mero vínculo milagroso y arbitrario, sino trascendental. Pero no por ello le han hecho oídos sordos al discurso científico. Han entrado en un cuerpo a cuerpo con él. A pesar de que, como veremos, para muchos intérpretes este ha sido un derrotero infausto para ambos -capaz de poner en duda el estatus mismo de su pensamiento filosófico-, en estas páginas investigaremos los resultados benéficos de esta confrontación, que se harán visibles a partir de su estudio comparado. Tal estudio comparado es problemático, ya que estos dos autores aparecen como figuras contrapuestas, incluso incompatibles. Al punto que se podría afirmar que para Deleuze la lógica hegeliana es una nueva máscara para los mismos borceguies españoles, su Concepto no menos pretencioso, arbitrario e inexistente que las nociones de los alquimistas ${ }^{6}$, y que para un hegeliano la filosofia de Deleuze es un mero conglomerado posmoderno, rapsodia de afirmaciones erráticas sin lazo espiritual. Pero en su posicionamiento en torno a las ciencias de su época, se observa que la lógica hegeliana y la filosofia de la diferencia deleuziana comparten una búsqueda común, que pone sus cuerdas en apariencia discordantes en una particular armonía.

\section{Filosofia de la naturaleza, del orden germano al caos a la francesa}

El rol de la ciencia en Hegel y Deleuze ha sido objeto de despiadadas críticas. Hegel fue embestido de frente por Karl Popper en La sociedad abierta y sus enemigos (1945) ${ }^{7}$, Deleuze y Guattari fueron condenados sumariamente por

de lo pretencioso de su conocimiento" (Brians, P., Study Guide for Goehte's Faust). Disponible en: http://public.wsu.edu/ brians/hum_303/faust.html. Revisado el 6 de octubre de 2014.

6 Muchos deleuzianos han pensado que con la filosofia de Hegel eran meros borceguíes españoles y que para alcanzar el verdadero pensamiento bastaba con "quitárselos". El caso paradigmático, por la influencia que tendría en el resto de las interpretaciones es el de Hardt: "[Deleuze] se ocupó del hegelianismo no para salvar sus elementos valiosos, no para extraer 'el corazón racional de la caparazón mística', sino para articular una crítica total y un rechazo del marco de la dialéctica negativa para alcanzar una autonomía real, una separación teórica de toda la problemática hegeliana" (Hardt, M., Gilles Deleuze, an Apprenticeship in Philosophy, Mineápolis: University of Minnesota Press, 1993, p. XI). La tendencia se ha revertido en los últimos años con una serie de estudios que contemplan la posibilidad de un fructífero análisis comparado como el que hacemos aquí, cuya muestra paradigmática es el libro de Houle, K. y J. Vernon (eds.), Hegel and Deleuze, Together Again for the First Time, Evanston: Nothwestern University Press, 2013.

7 "Hegel logró hacer los milagros más fabulosos. Maestro de la lógica, para él era un juego de niños extraer mediante sus poderosos métodos dialécticos, palpables conejitos físicos de sus galeras puramente metafisicas... Hegel logró 'probar' mediante métodos puramente filosóficos (ciento catorce años después de los Principia de Newton) que los planetas se movian de acuerdo con las leyes de Kepler. Llegó a elaborar, incluso, la deducción de la posición real de los planetas, demostrando de este modo que no podía haber ningún planeta entre Marte y Júpiter (desgraciadamente, no se enteró a tiempo de que dicho planeta había sido descubierto unos pocos meses antes). De forma similar, demostró que la imantación del hierro supone un aumento de peso, que 
Alan Sokal en sus Imposturas intelectuales (1997) donde habria declamado que el rey de la French Theory estaba desnudo ${ }^{8}$. Creo que la furia de Popper y Sokal radica en una confusión común: ni Deleuze ni Hegel hacen un uso científico de la terminología científica. Han ejercido, más bien, lo que Foucault ha llamado "su derecho a explorar lo que, en su propio pensamiento, puede ser cambiado por el ejercicio que hace de un saber que le es extranjero" 9 . La ciencia no es la verdad de la verdad, no es la "prueba" de la verdad de una filosofia (ni, por cierto, la filosofia es la fuerza que adviene para llevar a la ciencia por el buen camino). Para la filosofía, la ciencia es una fuerza extraña (una entre otras).

las teorías newtonianas de la inercia y la gravedad se contradicen mutuamente (no pudo prever, por supuesto, que Einstein demostraria la identidad de la masa inerte y la gravitatoria) y otra cantidad de cosas por el estilo... La obra de Hegel halló eco entre aquellos que prefieren la rápida iniciación en los profundos secretos de este universo a los tecnicismos laboriosos de una ciencia que, después de todo, puede terminar por desilusionarlos por su falta de poder para revelar todos los misterios. En efecto, no tardaron en descubrir que nada podia aplicarse con tanta facilidad a cualquier problema de cualquier naturaleza y, al mismo tiempo, con tan impresionante aunque solo aparente dificultad y con tal rapidez, seguridad y éxito, o con mayor baratura y menor trabajo y adiestramiento científicos y, a la vez, con un aire docto más espectacular... El éxito de Hegel marcó el comienzo de la 'edad de la deshonestidad'... una nueva edad controlada por la magia de las palabras altisonantes y el irresistible poder de la Jengonza" (Popper, K., La sociedad abierta y sus enemigos, Loedel, E. (trad.), Madrid: Paidós, 2006, pp. 244-245). "En los años recientes, sin embargo, los académicos han comenzado a tomar la filosofia de la naturaleza de Hegel con más seriedad" (Houlgate, S., "Reason in Nature", en: An Introducton to Hegel, Malden: Blackwell, 2005). Esta mayor seriedad se observa en realidad a partir de la década del 70, con la edición en tres volúmenes de la traducción al inglés del texto completo, con los agregados, y una profusa cantidad de notas que reponen las relaciones con los diferentes científicos y teorias de la época, $c f$. Petry, M.J., Hegel's Philosophy of Nature, Londres: Allen and Unwin, 1970, y también Stone, A., Petrified Intelligence, Nature in Hegel's Philosophy, Nueva York: SUNY, 2005, p. XI: “...a través del trabajo de Hegel, podemos identificar un problema determinado con el abordaje científico: depende de supuestos metafísicos inadecuados. Dado que Hegel cree que existe una forma para investigar filosóficamente la naturaleza, basada en supuestos metafisicos diferentes y más adecuados, lo que su trabajo subsecuentemente implica es que existe una forma específicamente filosófica de investigar la naturaleza que puede proveer las bases para una manera de vivir más sustentable desde el punto de vista ambiental".

8 "[Examinando los textos de Deleuze y Guattari] encontramos una fuerte densidad de términos científicos, utilizados fuera de su contexto y sin lazo lógico aparente, al menos si atribuimos a esos términos su sentido científico habitual. Por supuesto, Deleuze y Guattari son libres de usar estos términos en sentidos diferentes: la ciencia no tiene el monopolio del uso de palabras tales como 'caos', 'límite' o 'energía'. Pero, como vamos a mostrar, sus textos están repletos de términos muy técnicos que no son utilizados normalmente fuera de discursos científicos muy precisos... Somos conscientes de que Deleuze y Guattari se ocupan de filosofia y no de divulgación científica. Pero, ¿qué rol filosófico legítimo puede efectuar esa avalancha de terminologia erudita mal digerida? Nuestra opinión es que la explicación más plausible es que los autores dan muestra, en sus escritos, de una erudición vasta pero muy superficial" (Sokal, A., Impostures intellectuelles, París: Odile Jacob, 1997, pp. 211-212). Más adelante, acepta que "un defensor de Deleuze podría sostener que estas palabras son utilizadas en sentido filosófico o metafórico", pero descarta esta opción por motivos inciertos (ibid., p. 224, nota).

9 Foucault, M., Histoire de la sexualité, v. II, Paris: Gallimard, 1984, p. 16. 
Pero la filosofia no es contemplación ni representación, sino reflexión sobre el pensamiento, y sobre aquello que en el pensamiento cambia en su encuentro con lo extraño que, en este caso, es el saber científico. Qué nos dice lo otro del pensamiento del pensamiento mismo, en eso, y no en una epistemología o filosofia de la ciencia, consiste el proyecto de una filosofia de la naturaleza en el que Hegel y Deleuze se inscriben ${ }^{10}$.

Para indagar acerca de los efectos concretos que tiene para el pensamiento de Hegel y Deleuze su puesta en relación con el corpus científico, tomaremos la segunda parte de la Enciclopedia de las ciencias filosóficas de Hegel (más específicamente la Física Orgánica, "la realidad singular [einzelnen Wirklichen] que es la unidad de la universalidad y la realidad [Wirklichkeit]"11) y tres capítulos de Mil mesetas de Deleuze y Guattari ("Rizoma", "La geología de la moral" y "Devenir-animal, devenir-intenso, devenir-imperceptible"). A partir de una puesta en serie de estos textos (organismo geológico-geología de la moral; organismo vegetal-rizoma; organismo animal-devenir-animal) es posible iniciar un diálogo fructífero entre ambos autores.

En efecto, la relación reciproca nos permite matizar las distancias inconmensurables que la impresión inmediata de los textos parece establecer (alli donde Hegel es como siempre sistemático, Deleuze rompe como nunca con el viejo estilo ${ }^{12}$ ). Por un lado, la luz de la sistematicidad hegeliana permite localizar las distinciones y determinaciones presentes -aunque a veces ahogadas-

\footnotetext{
${ }^{10}$ Se inscriben así en la línea trazada de los presocráticos a Schelling: "Hacer de lo objetivo lo primero, y deducir de alli lo subjetivo, tal es la tarea de la Filosofia de la naturaleza" (Schelling, F.W.J., System des transzendentales Idealismus, Hamburgo: Meiner, 1957, p. 10, SW 242). Hegel lo hace en forma explícita y Deleuze en forma implícita: "[La doctrina del ser] le permite a Deleuze renovar el proyecto hace tiempo olvidada de una filosofia de la naturaleza" (Gualandi, A., Deleuze, París: Les Belles Lettres, 1998, p. 25). Se puede indicar asimismo la influencia que la concepción de uno de sus referentes filosóficos, Gilbert Simondon, tenía de la naturaleza: "Podríamos llamar naturaleza a esa realidad pre-individual que el individuo lleva consigo, buscando reencontrar en la palabra naturaleza el significado que le daban los filósofos presocráticos... la Naturaleza no es lo contrario del Hombre, sino la primera fase del ser" (Simondon, G., L'individuation, à la lumière des notions de forme et d'information, París: Millon, 2005, p. 305).

${ }^{11}$ Hegel, G.W.F., Enzyklopädie, Werke in zwanzig Bänden, v. IX, p. 268. Y lo es acercando los tres círculos o silogismos: U-S-P, P-U-S y S-P-U (donde la universal = el género, lo particular = lo inorgánico, y lo singular = lo orgánico). Es decir que lejos de ser "sin concepto", la física orgánica realiza la actividad del concepto por excelencia, que es el movimiento y entrelazamiento entre las formas silogisticas: es término medio que reúne inmediatamente lo inorgánico y el género, es conclusión de la fuerza de la negatividad (lo inorgánico-extrínseco como premisa mayor meramente mediada por el género) y realización a través de lo inorgánico del género. Cada silogismo del silogismo total de lo orgánico corresponde a uno de los momentos que analizaremos en estas páginas.

${ }^{12}$ Si bien el terreno más fértil para trabajar la relación con Hegel en Deleuze es Diferencia y repetición, optamos en este artículo por Mil mesetas en pos de extremar la tensión entre ambos autores.
} 
dentro del caos de la terminología de Deleuze y Guattari. Hegel funciona como unos borceguíes españoles que impiden a Deleuze y Guattari divagar como un fuego fatuo de aquí para alli, les da una voz concreta y los determina. El corpus científico no es así solo un objeto a corroer y aniquilar por la actividad esquizofrénica, sino también un elemento que permite trazar distinciones ontológicas fundamentales. Por otro lado, el caos de Mil mesetas, el borramiento constante de las fronteras conceptuales permite, mejor que el orden de Hegel, comprender la especificidad del proyecto de una filosofia de la naturaleza que no es una mera repetición de la ontología, sino un esfuerzo por comprender la singularidad en su efervescencia, en sus desvios, aberraciones e imperfecciones.

a) Desde la perspectiva de Hegel, la confrontación permitirá poner de relieve que la filosofia de la naturaleza no es una mera descripción mecánica del trabajo del concepto lógico que, como fuerza extrínseca, insertaría paulatinamente sus determinaciones en una materia a-conceptual meramente pasiva. Si así fuera, la lógica hegeliana se transformaría en materia del Collegium Logicum que Goethe satiriza, en unos borceguies españoles que torturan lo "natural", lo aplastan, y le quitan todo lo que le es específico. Tal interpretación existe, y tiene su base textual ${ }^{13}$, pero se trata de una interpretación cruel y, sobre todo, carente de todo interés reflexivo, de las largas páginas y extensos cursos que Hegel dedicara a la naturaleza.

Es cierto que la naturaleza sería una mera colección de determinaciones extrínsecas, contingentes y finitas si no fuera por la "consideración pensante" [denkende Betrachtung der Natur], en tanto universal concreto ${ }^{14}$. El concepto como actividad de la idea es el lazo espiritual que liga lo que para las ciencias

\footnotetext{
13 "El reino de sus formas es la indeterminación y el juego en sí mismo; el concepto no se toma de ellas, sino que deben ser medidas por el concepto" (ibid., p. 367). "El mago que otorga a esta semilla, que aplasto con mi mano, un sentido muy distinto [al propio de la naturaleza, esto es, sin concepto]: el concepto de la naturaleza" (ibid. p. 396). No es la fundamentación textual, sino el interés de tales interpretaciones lo que está puesto en cuestión. Esta interpretación sin interés es la que lleva a Deleuze a rechazar la filosofia de la naturaleza de Hegel: "Por eso se dice que la Naturaleza es concepto alienado, espiritu alienado, opuesto a sí mismo... es partes extra partes, mens momentanea" (Deleuze, G., Différence et répétition, París: PUF, 1968, p. 24). Sobre el rol de la alienación en la filosofia de la naturaleza de Deleuze, en tensa relación con el hegelianismo, $c f$. Colebrook, C., Deleuze and the Meaning of Life, Nueva York: Continuum, 2010, pp. 13-31. Sobre la solución escéptica al conflicto entre concepto y naturaleza, cf. Pinkard, T., Hegel's Naturalism, Mind, Nature and the Final Ends of Life, Nueva York: Oxford University Press, 2012, pp. 19-22 ("la mejor concepción de la naturaleza es cualquier cosa que las ciencias naturales determinen que es el caso", pero "por sí misma, la naturaleza es incapaz de organizarse", es impotente y depende del concepto). 14 Hegel, G.W.F., Enzyklopädie, Werke in zwanzig Bänden, v. IX, p. 15 [304].
} 
empíricas aparece fragmentado ${ }^{15} \mathrm{y}$, en ese sentido, es la "causa final" de la naturaleza. Pero esa causalidad final-conceptual no puede ser considerada como si el concepto fuera un titán ubicado al final de la línea del tiempo, tirando de ella como de una cuerda en una cinchada y arrastrando los vagones de la naturaleza hacia su destino final. Tal sería el punto de vista finito, que Hegel descarta explícitamente: "La relación finalística exige de suyo un modo de comprensión más profundo que [la consideración] con arreglo a relaciones externas y finitas; exige [a saber] el modo de consideración [propio] del concepto el cual, según su naturaleza en general, es inmanente y [lo es] por tanto a la naturaleza en cuanto tal" 16 .

El concepto no puede ser un esqueleto formal, no puede venir de afuera, tiene que ser determinación intrínseca (de lo contrario, ¡mal podría ser llamado conceptual!). Si fuera extrínseco y se aplicara como un molde a la naturaleza "sin concepto", la relación entre ambos sería "externa y finita", es decir, que el concepto se articularía con la naturaleza de modo no conceptual, lo cual es a todas luces absurdo (como también lo es pensar que en la naturaleza el concepto tiene la misma lógica que en la Idea). La concepción de la naturaleza como mera negación traiciona la propia empresa hegeliana, transformando a Hegel en un mero copista que acumula folios pensando en cobrar el precio por página del mercado alemán de principios de siglo XIX. Intentaremos mostrar que la filosofia de la naturaleza de Hegel no es una naturaleza muerta filosófica. Solo así cobrará sentido (y función conceptual) su rol como uno de los tres miembros del silogismo de silogismos con el que cierra la Enciclopedia ${ }^{17}$. Si bien es claro que Hegel coloca el énfasis en el rol del elemento lógico, y la fuerza del plano espiritual es innegable (acogiendo al derecho, la religión, el arte y la filosofia misma), ninguna de las figuras del silogismo de silogismos funcionaria si la naturaleza fuera un mero casillero vacio. Todos los miembros ocupan todos los lugares: premisa mayor, término medio y conclusión. Cuanto más nos importen la lógica y el espíritu, más se hace imperioso encontrar el sentido de la naturaleza. Pese a que la naturaleza es la esfera de la diferencia desatada y el concepto la de la identidad ambas solo están contrapuestas en el entendimiento. La razón capta que la identidad del concepto no es monolitica

\footnotetext{
15 "El contenido determinado de la fisica, fuera de lo universal, está despedazado, desmembrado, asilado, segregado [zersplittert, zerstückelt, vereinzelt, abgesondert]" (ibid., p. 21).

16 Ibid., p. 13 [303-304].

17 Silogismo de silogismos: 1) Idea-Naturaleza-Espíritu. 2) Naturaleza-Espíritu-Idea. 3) EspírituIdea-Naturaleza (cf. ibid., v. X, pp. 393-394 [603-604]). Cf. infra, nota 91.
} 
sino "diamantina", es decir, que contiene, y contiene necesariamente, la diferencia en su seno ${ }^{18}$ (lejos de anularla como algunas interpretaciones tienden a pensar ${ }^{19}$ ). La fuerza caótica de la naturaleza se transforma así en exigencia.

b) Desde la perspectiva de Deleuze y Guattari, la hipótesis que nos guía es que la naturaleza es mucho más que un caos y flujo indeterminado que hace estallar todos los intentos de la ciencia de apresarlo en sus funciones $^{20}$. Si la lectura unilateral en el caso de Hegel hace pensar que su filosofia anula la diferencia en favor de una identidad, en el caso de Deleuze lleva a creer que son diferencias, nada más que diferencias, incapaces de constituir o dar cuenta de ninguna de las unidades que se presentan en la experiencia, rapsodia de percepciones que no podrían encontrar ninguna unidad ${ }^{21}$.

Contra esa corriente de los estudios deleuzianos (y del anti-deleuzianismo) que ve en Deleuze un apólogo del caos, el flujo y la disolución de toda forma, intentaremos mostrar la importancia de la determinación en Deleuze. Ocurre que este, sobre todo en sus obras en conjunto con Guattari, tiende a dar por sentadas las determinaciones que necesariamente supone. Pero no hay diferencia pura, desnuda. Toda diferencia está envuelta necesariamente en identidades, aunque sean evanescentes. Aunque esas identidades sean efectos, lo que Deleuze llama imagen clásica o dogmática del pensamiento los toma como fundamento y construye un sistema puntual a partir de ellas. Esta imagen no es un factum, sino que debe ser elaborada: "Elaboramos un sistema puntual o una representación dialéctica, pero con el objeto de hacerla crujir, de llevar

\footnotetext{
18 "Para la universalidad filosófica las determinaciones no son indiferentes; es la universalidad que se llena a sí misma, que en su identidad diamantina también contiene en sí la diferencia" (ibid., p. 21). La referencia al diamante como figura de la identidad remite a la turmalina y a la "esmeralda en sus faces oculta una ondina de frente clara" de Víctor Hugo referidos por Deleuze en Différence et répétition, pp. 286-287.

19 Tomemos a Adorno como un ejemplo entre un océano infinito en la misma línea: "Todo lo que yace fuera de la identificación con el principio universal es considerado como absolutamente insignificante, efimero y sin importancia" (Adorno, T., Metaphysik, Begriff und Probleme, Fráncfort d.M.: Suhrkamp, 1998, pp. 125-126). En esta línea está incluida, por cierto la interpretación de Deleuze: "[en Hegel] la diferencia es empujada hasta el final, es decir hasta el fundamento que no es menos su retorno o su reproducción que su aniquilación” (Deleuze, G., Différence et répétition, p. 65).

${ }_{20}$ "La ciencia no tiene por objeto conceptos, sino funciones" (Deleuze, G. y F. Guattari, Qu'est-ce que la philosophie?, París: Minuit, 1991, p. 111).

21 "Una rapsodia de percepciones que no se podrian hacer compatibles entre sí en ningún contexto... y por consiguiente tampoco con la unidad trascendental y necesaria de la apercepción" (Kant, I., Crítica de la razón pura, Caimi, M. (trad.), Buenos Aires: Colihue, 2009, p. 253 (B195)).
} 
a cabo una sacudida sísmica. Un sistema puntual será más interesante en tanto un músico, un pintor, un escritor o un filósofo se le opongan, e incluso lo fabrique para oponerse a él, como un trampolín para saltar"22.

El sistema puntual constituido a partir de las identidades ("puntos") debe primero existir para que sea posible hacerlo crujir. Por más que Deleuze y Guattari la supongan como dada, la imagen del pensamiento debe ser producida. Ocurre que raramente la elaboran ellos mismos, porque consideran que ya ha sido construida por el largo esfuerzo del pensamiento occidental por la "más extraña alianza: entre la ciencia, el buen sentido y la filosofia"23. La dialéctica hegeliana es un caso de esas imágenes del pensamiento que están para Deleuze ya allí (como no podría ser de otra manera para un individuo que se formó en filosofia en Francia en la década del 40, bajo el imperio de Kojève y el primer Hyppolite ${ }^{24}$ ). Si nosotros la ignoramos, no comprendemos la operación deconstructiva, la pars destruens de su planteo. No sabemos qué cruje, sobre qué estratos geológicos se produce el movimiento sísmico. Quedamos desorientados, en el espacio vacío del filosofar que cree ingenuamente estar empezando de cero.

En el campo de la filosofia de la naturaleza, la imagen a la que Deleuze se opone "como trampolín para saltar" es la versión de una naturaleza hegeliana muerta, inerte material para un concepto extrinseco. ¿Y hacia dónde salta? Hacia pensar la lógica propia de la naturaleza, donde las diferencias salvajes tengan prioridad ontológica sobre las unidades que constituyen. El juego caótico, el flujo asfixiante de terminología técnica de Deleuze y Guattari, busca desmontar la lógica cientificista y su sistema puntual, a los cuales esos mismos términos remiten. Pero no por ello renuncian a pensar lo que está más allá de las fronteras de nuestro pensamiento. Por el contrario, emprenden el gesto último de pensar lo que existe sin nosotros, con otra lógica y otras determinaciones que las nuestras. Pero determinaciones al fin. Y allí es donde se reúne con la empresa de la filosofia de la naturaleza hegeliana tal como proponemos pensarla en estas páginas.

En suma, el estudio comparado de las perspectivas de Hegel y DeleuzeGuattari nos permitirá alcanzar una concepción de la filosofia de la naturaleza donde esta no sea una determinación despótica o un borceguí español como se

${ }^{22}$ Deleuze, G. y F. Guattari, Mille plateaux, Paris: Minuit, 1980, pp. 362-363.

${ }^{23}$ Cf. Deleuze, G., Différence et répétition, p. 288.

${ }^{24}$ En realidad, la representación de la dialéctica hegeliana como sistema de identidades, como Kojêve y el primer Hyppolite la han difundido: el hegelianismo. 
ha pensado a Hegel, ni de una indeterminación anárquica como se ha pensado a Deleuze. A pesar de la diferencia en el énfasis, ninguna de las dos filosofias ha pensado una identidad que pudiera existir sin diferencias, ni una diferencia que pudiera existir sin identidad. El sentido del mundo consiste en el cruce de la determinación y lo indeterminado en la determinabilidad del pensamiento. En la lectura comparada de ambos autores, podremos ver de qué manera coinciden en esa concepción de la filosofia y el sentido, cómo el otro lado de aquello que enfatizan tiene el mismo peso ontológico (aunque no expositivo) ${ }^{25}$. Univocidad del ser26, una misma voz para todo lo que es, sea identidad, sea diferencia, con precisos roles en la constitución del trémulo espacio en el que vivimos.

II. Scala naturae: animales embalsamados, que se agitan como locos y dibujados con un pincel finísimo de pelo de camello

La scala naturae o "árbol de la vida" tiene una larga historia en filosofia, que se remonta al Timeo de Platón y al De Anima aristotélico, apasionadamente abrazada en la Edad Media, objeto de un singular fanatismo de los naturalistas de la modernidad temprana. Paradigma del orden y la clasificación, es uno de los objetos predilectos de la crítica deleuziana ${ }^{27}$ : minerales, plantas, animales, hombres, en creciente gradación (como diferencias a "trazo grueso", enriquecidas y afinadas por cada propuesta de grilla clasificatoria, y el trabajo de cada disciplina particular: botánica, zoologia, mineralogía, etcétera).

\footnotetext{
${ }^{25}$ Esto no quita las distancias conceptuales profundas entre ambos autores, como por ejemplo su concepción del problema del comienzo en la filosofia. Al respeto, $c f$. Ferreyra, J., "El problema del comienzo en Hegel y Deleuze", en VIII Jornadas de Investigación en Filosofia, La Plata: 27 al 29 de abril de 2011. Disponible en: http://www.memoria.fahce.unlp.edu.ar/trab_eventos/ev.1281/ ev.1281.pdf. Revisado el 6 de junio de 2016.

${ }^{26}$ Cf. Deleuze, G., Différence et répétition, pp. 52ss.

${ }^{27}$ Burlada por la famosa clasificación borgeana que abre Las palabras y las cosas (libro con el que por cierto Diferencia y repetición establece un diálogo estrecho): "Este libro nació de un texto de Borges. De la risa que sacude, al leerlo, todo lo familiar al pensamiento -al nuestro: al que tiene nuestra edad y nuestra geografia-, trastornando todas las superficies ordenadas y todos los planos que ajustan la abundancia de seres, provocando una larga vacilación e inquietud en nuestra práctica milenaria de lo Mismo y lo Otro. Este texto cita 'cierta enciclopedia china' donde está escrito que 'los animales se dividen en a] pertenecientes al Emperador, b] embalsamados, c] amaestrados, d] lechones, e] sirenas, f] fabulosos, g] perros sueltos, h] incluidos en esta clasificación, i] que se agitan como locos, j] innumerables, k] dibujados con un pincel finísimo de pelo de camello, 1] etcétera, $\mathrm{m}$ ] que acaban de romper el jarrón, n] que de lejos parecen moscas" (Foucault, M. Las palabras y las cosas, Frost, E. (trad.), Buenos Aires: Siglo XXI, 1968, p. 1. La cita de Borges proviene de Borges, J.L., "El idioma analitico de John Wilkins", en Otras inquisiciones, Buenos Aires: Emecé, 1960, p. 142.
} 
A primera vista, Hegel aparece apegado a esta tradición y Deleuze al esfuerzo de hacer su crítica radical. En efecto, la estructura expositiva de la filosofia de la naturaleza de Hegel sigue la línea ascendente de la escala de la naturaleza, poniendo los pies en lo inorgánico para elevarse paulatinamente hacia las plantas, de alli a los animales, para llegar finalmente a los hombres (cuya diferencia de naturaleza y ya no "meramente" de grado con los animales está subrayada por la inclusión del hombre en otra parte de la Enciclopedia, otro miembro del silogismo de silogismos -espíritu y ya no naturaleza, incluso en lo que respecta a su cuerpo y su fisiología-, cumpliendo el sueño antropológico que Max Scheler expresará bellamente: oponer al hombre "del modo más riguroso al 'animal en general' y, por lo tanto, también a todos los mamíferos y vertebrados y a estos, en el mismo sentido que, por ejemplo, al infusorio Stentor"28). Frente a esto, Deleuze propone una inversión en principio radical (más radical en tanto no es una mera inversión, no es un mero cambio de sentido en la escala, sino una impugnación de la lógica subyacente): el hombre se enfrenta a un imperativo moral curioso en tanto debe devenir animal, y el animal, por su parte, devenir molecular. La "molar" escala de la naturaleza se disuelve en el imperceptible mundo de las diferencias infinitesimales.

Sin embargo, si nuestra hipótesis interpretativa es adecuada, si hay una lógica propia de la naturaleza, la cuestión en Hegel no puede tratarse de un mero ascender mecánico por la scala naturae para llegar al espíritu, ni en Deleuze limitarse a un mero derribar la escalera. Por un lado, ni la geología ni la vida vegetal ni la vida animal hegelianas son simples escalones que se trata de dejar atrás en pro de la elevación a la criatura eminente. Debajo, entre los peldaños de la escala de la naturaleza debe poder observarse la persistencia de elementos conceptuales vivos. Todas las diferencias deben enriquecer al concepto en tanto son parte de su identidad diamantina. Minerales, plantas y animales expresan la singularización de la vida del absoluto. El hombre no es en sí mismo la totalidad del absoluto (como el absoluto no es absoluto por estar quieto en sí). Entonces, algo del movimiento del absoluto se puede observar en el mineral, el vegetal, el animal, mas no en el hombre. El absoluto, qua planta, qua animal, qua tierra debe tener su modo de ser. Hay que devenir mineral, devenir vegetal, devenir animal para asomarse a esas facetas singulares del diamante del absoluto y su "shimmering light" (la Enciclopedia es el

\footnotetext{
${ }^{28}$ Scheler, M., El puesto del hombre en el cosmos, Gaos, J. (trad.), Buenos Aires: Losada, 1938 p. 29.
} 
viaje humano a través de esos devenires). Por el otro lado, las formas, figuras, conceptos y mesetas de Mil mesetas no se diluyen en un fondo caótico donde todas quieren decir lo mismo. Hay una especificidad del estrato geológico, del rizoma, del devenir, que puede ser pensada desde el esquema de la scala naturae (aunque no para intentar determinar su jerarquía sino su especificidad en su misma actividad de hacerla crujir). Los estratos pueden ser pensados como organismos geológicos, los rizomas como organismos vegetales, los devenires como relativos a organismos animales. Su vinculación no puede ser una mera inversión del buen sentido de la escala, no puede tratarse simplemente de descender alli donde la tradición asciende. No se trata de tomar el sentido inverso hacia lo imperceptible. No se trata de establecer una regresión, sino una involución: "regresar es ir hacia lo menos diferenciado, pero involucionar, es formar un bloque siguiendo su propia línea, 'entre' los términos puestos en juego y bajo las relaciones asignables" 29 . Involucionar no es regresar, sino crear; es, por lo tanto, ir hacia lo más diferenciado ${ }^{30}$. Podemos establecer la cadena involutiva cuerpo sin órganos-estrato-rizoma-devenir. Una vez establecida la serie (tomada la decisión de establecer la serie), observamos diferentes niveles de determinación. Para indagar en qué consisten precisamente, pondremos a Mil mesetas dentro de los borceguíes españoles de la Enciclopedia de las ciencias filosóficas, por un lado para establecer un corte dentro del caos y, por otro, para mostrar la vida propia de lo pensado por el mecanismo de los borceguíes, cómo resquebraja y vitaliza la supuesta prioridad ontológica del artilugio lógico.

\section{Geología de la moral y vida geológica}

Siguiendo el orden expositivo de Hegel en la última parte de la Filosofia de la naturaleza, la primera etapa de la vida es la geología. El capítulo de Mil mesetas correspondiente es el tercero: "10,000 av. j.-c. - La geología de la moral (¿quién se cree que es, la tierra?)”. Este texto se ubica, estilísticamente, a una distancia como nunca inconmensurable de Hegel. Está caracterizado por un extremo barroquismo, pareciendo comprobar la denuncia de Sokal: una "fuerte densidad de términos científicos utilizado fuera de su contexto y sin lazo lógico" ${ }^{3}$. Pero es totalmente falso que Deleuze y Guattari las utilicen alli "fuera

\footnotetext{
29 Ibid., p. 292.

30 Deleuze y Guattari no lo dicen explícitamente, pero el contrapunto necesario está implícito. Si regresar es ir hacia lo menos diferenciado, involucionar es ir hacia lo más diferenciado.

31 Sokal, A., Impostures intellectuelles, p. 211.
} 
de su contexto". Ocurre que ese contexto no es el discurso científico objetivo, sino justamente lo contrario: el discurso ficcional. En efecto, todo el capítulo en cuestión se presenta como el relato de una conferencia de un personaje de Sir Arthur Conan Doyle: el profesor George Edward Challenger. La forma narrativa elegida busca evitar la ambigüedad habilitada por Hegel que parece tomar la ciencia de su época como una serie de hechos puros ("lo que sea que las ciencias determinan que es el caso", según Pinkard ${ }^{32}$ ) y, por tanto, habilita las criticas que lo han atacado a partir de otro "hecho empírico" (el desarrollo de las ciencias: ¡qué desgracia, Hegel no se enteró a tiempo de que Ceres existía!). En contrapartida, con la elección de la perspectiva de un personaje ficcional, Deleuze y Guattari cierran el paso a esa posibilidad. La terminología científica no representa la verdad, ni aspira a hacerlo, sino que es en sí misma ficción ${ }^{33}$.

Tampoco es arbitraria la elección específica del personaje. Si bien fue opacado en el legado de Conan Doyle por el celebérrimo Sherlock Holmes, Challenger es un personaje de culto que aparece como la agresiva contracara de aquel detective analítico y desapasionado ${ }^{34}$. Mediante esta elección, de los dos géneros literarios entre los cuales oscila según Deleuze un libro de filosofia (en parte novela policial, en parte ciencia ficción ${ }^{35}$ ), el capitulo tres de Mil mesetas opta decididamente por el polo de la ciencia ficción, donde "la ciencia ya no tiene la llave que abre la mente humana, sino que fuerzas insondables gobiernan en un mundo de terror abrumador y angustia incontrolable"36. Así, en la boca de Challenger, la ciencia ya no es la armadura, los borceguíes españoles de nuestra comprensión del mundo, sino un reservorio de fuerzas insondables que los armazones racionales intentan domar.

La conferencia de Challenger cuya presentación el capítulo tres de Mil mesetas narra, es explícitamente presentada por Deleuze y Guattari como "mezcla de varios manuales de geología y biología de acuerdo a su humor

${ }^{32}$ Pinkard, T., Hegel's Naturalism, Mind, Nature and the Final Ends of Life, p. 22.

${ }^{33}$ La cual no significa "bajarle el precio" a los conceptos. Para la defensa de la noción de ficción en un sentido ontológico, $c f$. la interpretación de Mónica Cragnolini de las "ficciones útiles" en Nietzsche y su relación con los paralogismos como ficción necesaria en Kant (Cragnoli, M., Moradas nietzscheanas. Del sí mismo, del otro y del "entre", Buenos Aires: Ediciones La Cebra, 2006). El rol de la imaginación productora kantiana, reivindicada por los poskantianos en su carácter genético, marca el rol ontológicamente constitutivo de lo ficcional en la realidad efectiva, contrapuesta al dogmático postular la "realidad" como cosa en sí independiente de nuestro actuar.

${ }^{34}$ Deleuze tiene probablemente en mente el cuento "Cuando la tierra gritó" de 1928.

35 "Un libro de filosofia debe ser por un lado una especie muy particular de novela policial, por el otro una especie de ciencia ficción" (Deleuze, G., Différence et répétition, p. 3).

${ }^{36}$ Le Brazic, D., "Hélène Machinal. Conan Doyle: de Sherlock Holmes au Professeur Challenger", en: Journal of the Short Story in English, 48 (2007). Disponible en: http://jsse.revues.org/782. 
simiesco" 37 . El resultado es una jerga endemoniada, plena de pasajes que hacen la delicia de Sokal y los filosokalianos, que parecen confirmar su visión satírica de la French Theory: "[El profesor Challenger] explicó que la Tierra -la Desterritorilizada, la Glacial, la Molécula gigante- era un cuerpo sin órganos. Este cuerpo sin órganos estaba atravesado por materias inestables no formadas, flujos en todos los sentidos, intensidades libres o singularidades nómades, partículas locas o transitorias. Pero esa no era la cuestión por el momento. Pues, al mismo tiempo, se producía sobre la tierra un fenómeno muy importante, inevitable, benéfico en ciertos aspectos, lamentable en muchos otros: la estratificación. Los estratos eran las Capas, las Cinturas. Ellos consistian en formar las materias, apresar [emprisonner] las intensidades o fijar las intensidades... y hacer entrar a estas moléculas en conjuntos molares" ${ }^{38}$.

La alternativa a la lectura satírica es tratar de encontrar un orden en el caos aparente. En ese sentido, la jerga de este pasaje es susceptible de un primer ordenamiento en torno a la dualidad fundamental de la ontología deleuziana: lo virtual y lo actual. Estas páginas no presuponen su significado, relación e implicancias, sino por el contrario buscan contribuir a la larga tarea de dilucidarlos y hacerles justicia. Por el momento, sirven como primer eje ordenador: por un lado, lo virtual y su vocabulario específico (molécula, cuerpo sin órganos, desterritorialización, flujos, líneas de fuga, intensidades, problemas, etcétera); por otro lado, lo actual (estratos, molaridad, códigos, territorialización, soluciones, etcétera ${ }^{39}$. No hay que pensar la relación entre estos planos ontológicos como lo indeterminado enfrentado a la determinación, ya que cada uno de estos planos tiene su forma específica de determinación: lo virtual solo es indeterminado desde el punto de vista de lo actual y sus formas características de determinación. Sin embargo, no hay determinación actual sin una determinación virtual que presupone, ni determinación virtual sin determinaciones actuales que la recubran.

Hay un sesgo axiológico del vocabulario y que ha sido determinante en la constitución del sentido común de la interpretación de Deleuze: si los estratos

${ }^{37}$ Deleuze, G. y F. Guattari, Mille plateaux, p. 53.

38 Ibid., pp. 53-54. Sobre el rol de las cinturas en la morfologia animal, cf. Vialleton, L., Membres et ceintures des vertébrés tétrapodes, Paris: Doin, 1924, citado por Deleuze en Différence et répétition, p. 277 y por Deleuze, G. y F. Guattari en Mille plateaux, pp. 61-62.

39 Este dualismo simplista virtual-actual no dice nada concreto y podría ser arbitrariamente puesto en correspondencia con cualquier dualismo de la historia de la filosofia, desde Idea-copia en Platón hasta apolíneo-dionisíaco en Nietzsche. Pero se volverá progresivamente determinado en el curso de estas páginas. 
"aprisionan" a las intensidades deben ser malos, si las moléculas son "forzadas" a entrar en conjuntos molares deben ser "buenos salvajes". Pero se trata en realidad de una división ontológica que no debe ser confundida con una división moral. En el pasaje citado, Deleuze y Guattari sientan su posición en forma relativamente clara: el fenómeno de estratificación es "benéfico en ciertos aspectos, lamentable en muchos otros" y, por sobre todas las cosas, inevitable. Los borceguíes españoles son inevitables, e incluso benéficos en ciertos aspectos. Lo cual no quita que aquello que aprisionan (recubren, envuelven, visten) sea ontológicamente primero: "No se comprendia por qué en estas condiciones los estratos mismos estaban animados por movimientos de desterritorialización y decodificación relativos, que no estaban en ellos como accidentes. De hecho, lo que era primero era una desterritorialización absoluta, una línea de fuga absoluta, por muy compleja y múltiple que fuera, la del plano de consistencia o del cuerpo sin órganos (la Tierra, la absolutamente desterritorializada). Y solo se volvía relativa por estratificación sobre ese plano, ese cuerpo: los estratos era siempre residuos, y no a la inversa - no debíamos preguntarnos cómo algo salía de los estratos, sino más bien cómo las cosas entraban"40.

La desterritorialización absoluta es ontológicamente primera. Deleuze y Guattari bautizan tal prius caótico, anárquico, sin ninguna determinación, limite o forma que lo contenga con el célebre nombre de "cuerpo sin órganos" 41. Pero si bien la desterritorialización es absoluta, no puede decirse lo mismo de su indeterminación. La desterritorialización absoluta es "compleja y múltiple"42, es decir, que el cuerpo sin órganos solo es indeterminado desde el punto de vista de lo actual, pero posee una complejidad que habilita su determinación completa desde el punto de vista de lo virtual ${ }^{43}$. Sería equiparable -con las reservas pertinentes- a la Logik: solo el comienzo (el ser, puro ser) carece de toda determinación. El desarrollo de la lógica es el proceso de determinación que concluye en la idea absoluta, como totalidad completamente determinada desde el punto de vista lógico, pero carente de las determinaciones propias de la naturaleza y el espíritu. Completamente determinados, completamente

40 Deleuze, G. y F. Guattari, Mille plateaux, p. 74. El subrayado es mío.

41 Término extraído del magma de la producción literario-epistolar de Antonin Artaud y por tanto tentador para ser usado en un sentido literario y no filosófico.

42 Desde el punto de vista textual, el magma del vocabulario y la jerga constituyen el aspecto molecular, desterritoralizado, sobre el cual se trazan, ora sí, ora no, relaciones moleculares y estratificaciones molares. Por momentos quedan aprisionados, aquí tratamos de apresarlos un poco más.

43 "Lejos de ser indeterminado, lo virtual está completamente determinado" (Deleuze, G., Différence et répétition, p. 270). 
reales, pero carentes de determinación actual o Existenz: idea absoluta = cuerpo sin órganos ${ }^{44}$. Pero entonces, si el cuerpo sin órganos tiene su propia forma de determinación, ¿en qué aspectos el proceso de estratificación es benéfico? Fundamentalmente, porque abre una nueva vía de diferenciación: la determinación actual.

El capítulo sobre la "geología de la moral" puede así considerarse el punto cero del proceso de determinación actual. En efecto, la contraposición entre la Tierra (cuerpo sin órganos absolutamente desterritorializado) y los estratos indica que estamos ante la primera fase de dicho proceso. Sobre los estratos se montarán las conceptualizaciones más puntuales del rizoma y el devenir-animal, que estableceremos como niveles de una posible serie de su determinación progresiva de lo actual (que no debe confundirse con lo empirico).

En Hegel, en principio, la geología no ocupa el punto cero de la filosofia de la naturaleza. El espacio como primer estadio de la mecánica es la primera determinación de la naturaleza. Su característica es ser partes extra partes ("la abstracta universalidad de su ser-fuera-de-sí [Außersichseins]”"45). La geología aparece recién en la tercera sección, la física orgánica, la parte dedicada a la vida. Sin embargo, Hegel afirma que la geología es "la idea que ha llegado a la existencia [Existenz]"46. En ese sentido es posible conectarla directamente con la Idea absoluta, como Deleuze y Guattari la conectan con el cuerpo sin órganos. Se puede establecer una correlación entre la estratificación como momento inicial de la determinación actual en Mil mesetas y la geología como llegada de la Existenz en Hegel. La idea ya no es absoluta. Se vuelve, también en Hegel, relativa. Como en Deleuze y Guattari, la estructura interna de la tierra implica entonces que la desterritorialización absoluta del cuerpo sin órganos entra en un fenómeno de aprisionamiento y fijación.

Desde cierta perspectiva, el fenómeno geológico constituye un "aprisionamiento". En efecto, la idea está fijada en los estratos (Urfels, Schichten) ${ }^{47}$. Si Hegel fuera un fanático de los borceguies españoles en todas sus formas, sería un apologeta de los estratos. Pero, lejos de ello, los considera una detención del proceso, una interrupción del factor temporal. Representan en su fijeza,

\footnotetext{
${ }^{44}$ Cuerpo sin órganos = idea absoluta, ¡he aquí una equiparación polémica, pero no por ello menos pertinente y rica en potenciales desarrollos! Toda la correlación entre el tratamiento de la Idea en Diferencia y repetición y el cuerpo sin órganos en Mil mesetas, incluido el rol que Artaud cumple en la exposición de la primera, nos autoriza a hacerlo.

45 Hegel, G.W.F., Enzyklopädie, Werke in zwanzig Bänden, v. IX, p. 41 [312].

${ }^{46}$ Ibid., p. 337 [402].

${ }^{47}$ Cf. ibid., pp. 346-347.
} 
justamente en su fijeza, el aspecto alienado de la Idea, al punto que afirma que deben ser tomados solo como hechos y no pertenecen a la filosofia. La filosofia, por su parte, no es quietud, sino movimiento ${ }^{48}$. Es el concepto quien debe aportar movimiento a las determinaciones fijas de la geologia. Las relaciones, en tanto extrínsecas, deben ser medidas por el concepto: "no debe medirse al concepto por ellas, sino que ellas deben ser medidas por el concepto"49. El concepto, lejos de actuar como borceguies españoles, viene a liberarnos de ellos. Pero, ¿de qué manera nos libera? ¿Cómo entra en la existencia? ¿Un borceguí sobre los borceguíes? Una interpretación lineal, que considera el sistema de Hegel como una evolución mecánica, es incapaz de explicar cómo el despliegue de lo dinámico es meramente mecánico, y tampoco cómo el desarrollo mecánico de la naturaleza podría desembocar en la entrada en la existencia de la Idea que representa la fisica orgánica. ¿Cómo del Außersichsein de la mecánica y la fisica surgiría la entrada en la existencia de la Idea? Solo sería posible por la acción extrínseca de la idea. Pero eso sería paradojal: una acción extrínseca sacaría a la mecánica y a la fisica de la actividad extrinseca que las caracteriza, y la idea recurriría a un modo de acción carente de idea.

Pero ocurre que la filosofia de la naturaleza de Hegel no debe pensarse como una sucesión lineal (como el entendimiento la piensa), sino como silogismo (como la piensa la razón: el silogismo como máxima expresión de la lógica hegeliana). En tanto "primero de los silogismos de lo orgánico", en la geología el género, lo orgánico y lo inorgánico ocupan respectivamente los lugares estructurales de lo universal-singular-particular (U-S-P): lo orgánico (específico de la física orgánica que estamos considerando) es en tanto singular el término medio entre el género y lo inorgánico ${ }^{50}$. La geología no debe ser leída como pasaje de lo inorgánico a lo ideal, sino como momento singular que hace que lo universal pueda ser inorgánico a través de lo orgánico, y de esta manera ligarse a sí como lo que aparentemente está alienado de $\mathbf{s i}^{151}$. La Idea no es el

\footnotetext{
48 "Lo que pertenece a los estratos debe ser tomado como hechos; no pertenece a la filosofia... Los estratos han caído en la tierra, y así ésta se ha quedado quieta" (ibid., p. 347).

49 Ibid., p. 367.

50 "Lo orgánico se divide así en dos extremos universales, la naturaleza inorgánica y el género, cuyo medio es (U - S - P) y con los cuales es aquí todavía inmediatamente uno" (ibid., p. 368).

51 "La vida inmediata es así la vida alienada de sí, y es así la naturaleza inorgánica de la vida subjetiva. Porque lo inorgánico es todo exterioridad" (ibid., p. 340). Esta frase puede interpretarse como que la geología es todavía exterioridad, pero también como lo hacemos aquí: que es el modo en que la Idea se hace existencia y asi existe en medio de lo que se aliena de ella. Que la geología sea "la naturaleza inorgánica de la vida" no quiere decir que todavía esté perdida en lo meramente inorgánico (lo cual sería contradictorio, ya que es el primer estadio de lo orgánico, es organismo
} 
destino de la naturaleza (que alcanzaría cuando un día pueda desalienarse y devenir espíritu), porque la universalidad verdadera expresada por el silogismo "no ha sido una vez, sino que se produce eternamente" 52 .

Los términos del silogismo no se alternan ni se suceden linealmente, sino que coexisten en su diferencia. Como término medio el organismo geológico se escinde en género y naturaleza inorgánica. Así, lo orgánico tiene una vida propia, que también se produce enteramente como espíritu de lo inorgánico. La geología no se reduce al carácter fijo de los estratos, sino que también implica un dinamismo superador de la fijeza del Außersichsein. En tanto estrato, se liga a la particularidad de lo inorgánico pero también, y necesariamente, en tanto vida, lleva a las partes extrínsecas de lo inorgánico la intranquilidad universal como alma simple ${ }^{53}$ : en los estratos las partes extra partes que constituyen la Tierra vibran por la presencia de lo universal (que, en este sentido, y contra todo sentido común de lo que Hegel debería ser en la historia de la filosofia, sería lo Desterritorializado).

\section{Rizomas y raices en la vida vegetal ${ }^{54}$}

Uno de los más populares pasajes de la filosofia deleuziana es el que trata del rizoma. Concepto famoso que, benéfico en ciertos aspectos, pero lamentable en otros, ha llevado a los más profundos malentendidos. Ha sido leído como prueba de que la filosofia deleuziana sería la apología de un estado de absoluta e ilimitada libertad, donde el puro fluir y la indeterminación sería la regla. Y hay no pocas fórmulas que apuntalan tal interpretación, como la consigna: "¡haz rizoma y no raiz!" 55 . Pero, como en el caso de los estratos, Deleuze y Guattarí son explícitos en torno a la ausencia de valoración axiológica de este concepto: "no hay dualismo axiológico de lo bueno y lo malo" ${ }^{56}$. El rizoma no es bueno

geológico), sino que es la forma en que lo universal (la vida) tiene en sí su naturaleza inorgánica como algo que le es propio, inherente.

52 Ibid., p. 344.

53 Es la "física inferior" según Novalis: "La física inferior considera a la piedra entre las piedras - como la política ordinaria al hombre entre los hombres" (Novalis, L'encyclopédie, Wasmuth, E. (trad.), París: Minuit, 1966, p. 193). Pero también, para Novalis, "la mineralogía y la geología astronómicamente terrestres son otra cosa completamente. Habitualmente solo se incluyen fragmentos en la geognosia ordinaria - y su idea está contenida en la de la geognosia actual" (ibid.).

${ }^{54}$ La relación entre el pensamiento deleuziano y el de Hegel en torno a la confrontación del concepto de rizoma con la vida vegetal ha sido ya abordada en Somers-Hall, H., "La lógica del rizoma en la obra de Hegel y Deleuze”, en Houle, K. y J. Vernon (eds.), Hegel and Deleuze, Together Again for the First Time, pp. 54-75.

55 Deleuze, G. y F. Guattari, Mille plateaux, p. 36.

56 Ibid., p. 30. 
en sí mismo: "Un rizoma como tallo subterráneo se distingue absolutamente de las raíces y las raícillas. Los bulbos, los tubérculos son rizomas. Las plantas de raíz o raíz lateral pueden ser rizomorfas desde aspectos totalmente diferentes: el problema es saber si la botánica, con su especificidad, no es por entero rizomórfica. Los animales incluso lo son, bajo su forma de manada, las ratas son rizomas. Las madrigueras lo son, con todas sus funciones de hábitat, de provisión, de desplazamiento, de escabullimiento y de ruptura... En el rizoma existe lo mejor y lo peor: la papa y la grama, la mala hierba [chiendent]" ${ }_{57}$.

El rizoma no es mejor que su opuesto (el árbol, bella interioridad orgánica a partir de una lógica binaria basada en el principio: lo uno deviene dos ${ }^{58}$ ) sino que implica una lógica heterogénea. Ocurre que Deleuze y Guattari harán énfasis constante en la lógica del rizoma, porque consideran que epocalmente la lógica del árbol es dominante ${ }^{59}$. Pero de esto no debe concluirse una prioridad axiológica ${ }^{60}$. El nudo conceptual no está en el rizoma ni el árbol-raíz, sino en cómo se entrelazan ambos aspectos en lo actual.

Deleuze y Guattari parten de la convicción de que la lógica dominante es la de la escala de la naturaleza o del árbol de la vida. Y que esta actúa como borceguies españoles que asfixian al pensamiento: "Cada vez que un rizoma es tapado, arborificado, se acabó"61. Así, la mayor parte del capítulo acerca del rizoma trata de cómo poner en jaque los ordenamientos naturales ${ }^{62}$ y

57 Ibid., p. 13

58 Cf. ibid., p. 11.

59 "Es curioso, cómo el árbol ha dominado la realidad occidental y todo el pensamiento occidental, de la botánica a la biología, la anatomía, pero también al gnoseología, la teología, la ontologia, toda la filosofia...: el fundamento-raiz. Grund, raices y fundaciones” (ibid., pp. 27-28).

60 En las páginas acerca del rizoma (y las de Mil mesetas en general) tampoco está ausente una valoración negativa del rizoma, en tanto estructura del capitalismo. La fórmula “¿No es acaso lo propio del rizoma atravesar raíces, y confundirse a veces con ellas?” (ibid., p. 21) puede ser leída como un mandato ético-político (a las fuerzas revolucionarias de atacar el árbol occidental a golpes de hachas rizomáticas) pero también como un diagnóstico del paulatino ahorcamiento de las estructuras estatales (y el estado de bienestar en primer lugar) por parte del capitalismo en su etapa de desborde del capital financiero (descodificado, desterritorializado). No entraremos en estas páginas en la problemática política, la vinculación del Estado y el capital, y el cuestionamiento de la visión simplista según la cual Deleuze sería un pensador meramente anti-estatalista

110 (y por tanto, a partir de un razonamiento dualista, pro-capitalista, neoliberal, etc.). Basta señalar que la frase "el Estado ha sido el modelo del libro y del pensamiento", en lugar de implicar una impugnación directa de la figura del Estado, puede llevar a reevaluar la caracterización negativa del árbol y el fundamento. Para ese particular, cf. Ferreyra, J., "Deleuze y el Estado" en Deus Mortalis, 10 (2011-2012), pp. 265-286.

${ }^{61}$ Deleuze, G. y F. Guattari, Mille plateaux, p. 22.

62 Así el ejemplo de los virus que "en ciertas condiciones, puede conectarse con las células germinales y transmitirse como un gen celular de una especie compleja; más aun, podria huir, pasar a las células de una especie totalmente otra... Las comunicaciones transversales entre lineas diferenciadas confunden los árboles genealógicos” (ibid., pp. 17-18). 
ontológicos ${ }^{63}$. Pero también concibe la operación inversa: "relacionar las raíces y los árboles con un rizoma"64. Relacionar, reconectar las raíces y los árboles al rizoma. Lo cual habilita, aunque subsidiariamente, el juego interpretativo que estamos realizando aquí: conectar las imágenes arborescentes con el rizoma, el orden y el caos, mostrar de qué manera son parte de un mismo plano de inmanencia en su diferencia ontológica.

No se trata de reencontrar en el rizoma la presencia de un dualismo ontológico que señalamos en la geología (rizoma-árbol en lugar de cuerpo sin órganos-estrato, pero en ambos casos meras repeticiones de lo mismo respecto a la dualidad de base virtual-actual). El sentido de la hipótesis interpretativa que guía estas páginas es encontrar diferencias en los niveles de determinación. ¿Cuál es entonces la diferencia que introduce el concepto de rizoma? Mientras el estrato geológico implica una relación directa con la Tierra Desterritorializada, el rizoma por su parte supone una territorialización fija a partir de la cual avanzar. El rizoma implica una progresión en el grado de determinación respecto a los estratos (que implicaban, como vimos, el nivel cero de actualización): "Lo múltiple, debe ser hecho, no mediante el agregado continuo de una dimensión superior, sino por el contrario con la mayor simplicidad, a fuerza de sobriedad, al nivel de las dimensiones de las cuales disponemos, siempre n-1 (solamente así formamos parte de lo múltiple, sustrayéndonos siempre de él). Sustraer lo único de la multiplicidad que se quiere constituir; escribir a la n-1. Tal sistema podría llamarse rizoma"65.

En el rizoma se trata de simplicidad, de sobriedad. ¡Qué diferencia de espíritu respecto al profesor Challenger y sus excesos! Y sin embargo, el desbocamiento de la sintaxis y el vocabulario característico de la geología de la moral permanecen. ¿De qué simplicidad, de qué sobriedad se trata, entonces? Se trata de liberar un espacio ya ocupado: sustraer, respecto a dimensiones "ya disponibles", dimensiones que no son, no pueden ser otra cosa, que son

\footnotetext{
63 Deleuze y Guattari abandonan explícitamente el viejo sueño de un sistema a partir de un primer principio absoluto del cual todas las series desciendan: "Si es que, por el contrario, no debe existir simplemente uno o varios fragmentos de un sistema, como en el primer caso, o muchos sistemas, como en el segundo, sino que debe haber en el espíritu humano un perfecto y único sistema, entonces tiene que darse un tal principio fundamental supremo y absolutamente primero" (Fichte, J., Sobre el concepto de la doctrina de la ciencia, Navarro, B. (trad.), México D.F.: Centro de Estudios Filosóficos, 1963, pp. 26-27 (GA I2, 125)).

${ }^{64}$ Deleuze, G. y F. Guattari, Mille plateaux, p. 22.

65 Ibid., p. 13. El subrayado de "sistema" es mío.
} 
los estratos adquiridos durante la primera fase de diferenciación ${ }^{66}$. Los estratos son la base respecto a la cual la lógica rizomática sustrae. Pero no lo hace como regresión hacia lo menos diferenciado -no es un retorno al cuerpo sin órganos-, sino como modo de alcanzar un nuevo estadio de diferenciación. El rizoma crece en los estratos, pero ya no responde a la lógica geológica y a su grado de actualización. Expresa que el cuerpo sin órganos no se disuelve en los estratos, que la "prisión" es relativa, que la desterritorialización continúa operando aun en la existencia, aun en lo actual. Lo singular, lo existente, no es, como en la geología, solo limite, corte y orden. El dualismo no es virtual/actual, sino entre dos formas de existencia actual: dos lógicas de la vegetación, el árbol y el rizoma, ambos existentes. La "vida vegetal" expuesta en el capitulo sobre el rizoma es, toda entera, un nuevo grado de actualización respecto a la geología.

Esta diferencia entre grados de actualización se observa claramente en los desarrollos de Hegel, quien consideraba que ciertas formas aparentemente vegetales, como el musgo o el moho, no son aún vida vegetal, sino parte de la vida geológica: producción de lo indiferente que se repite en forma desnuda sobre lo que cubre ${ }^{67}$. La vida vegetal es, como el rizoma en Deleuze y Guattari, un nuevo grado de actualización. Hegel lo expresa en términos silogísticos. Si a la vida geológica le corresponde el primer silogismo de lo orgánico (U-S-P), a la vida vegetal le corresponde el segundo: P-U-S. Silogismo vegetal: inorgánicogénero-organismo; "lo orgánico es aquí así a través del género mediado con lo inorgánico (P-U-S)"68. La idea, lo universal, es el término medio que permite que lo inorgánico sea, haciendo que en los estratos también surja vida. La vida vegetal es siempre singularidad pero ahora conclusión, extraída de la tierra estatificada por la fuerza de lo universal (el género como representante de la Idea y el concepto, como forma no idéntica a la de lo lógico de ser del concepto). La tierra aúlla. Así, en la tierra, no en un cielo ideal, se producen diferencias y no meras proliferaciones. En términos deleuzianos: los estratos, librados a su propia lógica, solo se pondrían en forma mecánica a sí mismos. La tierra sería un gran árbol, donde cada estructura se repetiria idéntica en todo lo que es.

Solo en este contexto (y no en el de considerarlos como meros apologetas del caos y la proliferación anárquica) se puede comprender en qué sentido

\footnotetext{
${ }^{66}$ Aunque el rizoma sea el primer capitulo, la introducción, y la geología el tercero, lo consideramos ontogenéticamente previo, de acuerdo a la hipótesis que rige estas páginas.

67 Esa indiferente "vegetación verde que cubre la Tierra" es asignada por Hegel al organismo geológico ( $c f$. Hegel, Enzyklopädie, Werke in zwanzig Bänden, v. IX, pp. 365-367).

68 Ibid., p. 369. El subrayado de "es" es mío.
} 
Deleuze y Guatari van, en su concepción de lo vegetal, más allá que Hegel. Para el filósofo alemán, "la planta no ha llegado a la diferencia... En ella la diferencia es solo una diferencia formal; lo que pone como otro, no es un verdadero otro"69. Incluso el rizoma, que Hegel incluye en su clasificación de la vida vegetal (Rhizophora mangle ${ }^{70}$ ), implica reproducción por proliferación, sin desarrollo. Transformación inmediata. Hegel lo estudia en torno a la curiosa capacidad de algunas plantas de que sus partes se transformen en totalidades. Es una de las especies en las cuales basta que cualquier parte (por ejemplo, una rama) sea arrancada por un viento, para que forme raíces en otra parte. Las ramas del manglar (la Rhizophora mangle) se vuelcan sobre el suelo y se transforman en troncos. Pero el nuevo individuo formado por este proceso será idéntico al que le dio origen: no hay diferenciación, sino mecanismo. Los borceguíes españoles parecen estar haciendo su trabajo mortifero: hasta que no seas hombre, no habrá verdadera producción de diferencia (y aun entonces, hasta que no te disuelvas en el espíritu absoluto...).

Si la cuestión fuera tan lineal, si uno de los extremos del silogismo vegetal fuera puro mecanismo y el otro una mera proliferación, la mediación del universal no estaria operando. Si la transformación fuera inmediata, se trataría de un falso silogismo, con el género como falso término medio, y no como presencia de lo universal. Tiene que haber, en la vegetación singular y en la tierra particular, huellas de la acción de la mediación espiritual que las articula. En caso contrario, ningún espíritu podría vestir a la tierra de vida. Con el rizoma, Deleuze y Guattari no realizan una apología de lo indeterminado, sino que encuentran en esa figura que Hegel habia tratado en forma marginal, el potencial necesario para que el concepto de la naturaleza vivifique la rígida progresión de la vida animal ${ }^{71}$.

\section{Devenir-animal y vida animal}

Continuando la senda de la determinación progresiva de la ontología de Deleuze y Guattari de acuerdo al adiestramiento dictado por la escala de

\footnotetext{
69 Ibid., p. 372.

70 Ibid., p. 383.

71 En este sentido, coincidimos con Somers-Hall quien afirma: “¿En qué sentido la concepción hegeliana de la planta puede ser comparada con el concepto de rizoma en Deleuze? En ambos casos, tenemos sistema sin un punto central de unidad, y que no opera de acuerdo con la lógica binaria que gobierna la estructura del pensamiento" (Somers-Hall, H., "La lógica del rizoma en la obra de Hegel y Deleuze", en Houle, K. y J. Vernon (eds.), Hegel and Deleuze, Together Again for the First Time, p. 64).
} 
la naturaleza, la próxima fase es la animalidad, y el lugar privilegiado para rastrearla el capítulo diez de Mil mesetas: "Devenir-intenso, devenir-animal, devenir-imperceptible". Pero los obstáculos de esta forzada, necesariamente forzada, via interpretativa se presentan de inmediato, ya que Deleuze y Guattari afirman explícitamente la identidad entre el devenir, el rizoma y el cuerpo sin órganos o Molécula: "devenir es un rizoma" 72 y "todos los devenires son moleculares. [La posibilidad de devenir] marca la pertenencia a una misma molécula, independientemente de los sujetos considerados y las formas consideradas"73.

Pero si el devenir es en algún sentido cuerpo sin órganos, y en algún sentido rizoma también es, en algún sentido, más que cuerpo sin órganos, y más que rizoma. Una forma del devenir es la "rizófera", que opera la alianza entre las raíces jóvenes y ciertos microorganismos, pero el virus $\mathrm{C}$, que opera la alianza entre el gato y el babuino, es otra forma de devenir ${ }^{74}$. Ambos tipos de alianzas son devenires, pero el nivel de heterogeneidad de los elementos puestos en juego se ha potenciado. Y esto justamente porque la rizomática sobre la cual se monta el concepto de devenir es mucho más compleja que los estratos geológicos que sirven de base a la rizófera.

Es cierto que "lo que es real es el devenir mismo, el bloque de devenir, y no los términos que se suponen fijos por los cuales pasaría el que deviene" 75 . Es cierto que hay una realidad, una efectividad del devenir respecto a la cual la existencia de los términos, de los contenidos, de las determinaciones es subsidiaria. Es cierto, incluso, que devenir imperceptible, indiscernible e impersonal son señalados como "virtudes"76. Es cierto que "suprimir de sí todo lo que nos impedía deslizarnos entre las cosas" aparece como un imperativo ${ }^{77}$. Pero si nos desprendemos de todo contenido posible la involución se convierte

${ }^{72}$ Deleuze, G. y F. Guattari, Mille plateaux, p. 292.

73 Ibid., p. 334.

74 "Hay un bloque de devenir que atrapa al gato y al babuino, y en el que un virus $\mathrm{C}$ opera la alianza. Hay un bloque de devenir entre las raices jóvenes y ciertos micro-organismos, en el cual la alianza es operada por las materias orgánicas sintetizadas en las hojas (rizófera)" (ibid., pp. 291-292).

75 Ibid., p. 291.

76 Ibid., p. 343. La "carga" axiológica de los conceptos ontológicos en Deleuze y Guattari vuelve a interpelarnos (asi como lo hacia el capítulo sobre los estratos cuando decían que estos "aprisionaban" las intensidades, y el del rizoma cuando indicaba que "hacer rizoma y no raíz" era un imperativo). Pero una vez más, como veremos, esta carga axiológica está epocal y geográficamente condicionada en un tiempo donde la fuerza de las estructuras arborescentes, estratificadas, etc. aparecía como claramente dominante. El neo-liberalismo aparentemente triunfador era (aún) solo un espectro.

77 Ibid., p. 344 
en regresión ${ }^{78}$. El devenir juega siempre entre los bordes, y en los bordes, aparecen las determinaciones a las que estamos habituados: estratos, plantas, animales, especies e individuos con el nivel de determinación que a cada uno le es propio. Moléculas, sí, pero también ratas y lobos y ballenas. Mujeres y niños y hombres. Sin gato, babuino, micro-organismos, pulga, león y cangrejo, el devenir sería mera conexión entre heterogéneos indeterminados, y por tanto idéntico al rizoma.

Para "suprimir todo lo que nos impedía deslizarnos entre las cosas" tiene que haber "cosas". Si todo ha sido suprimido y solo queda el "entre" el devenir se torna inviable. Si todo fluye y no cesa de fluir sin formas ni referencias, desaparecen las determinaciones y los reparos. Es por eso que los borceguíes españoles hacen falta, son benéficos. Los términos que aparecen en los bordes tienen necesariamente que surgir ${ }^{79}$, aunque el devenir no los produzca ${ }^{80}$. Hay univocidad, el ser se dice de la misma manera de todo lo que es ${ }^{81}$, pero lo hace sin aniquilar lo que es, sin nihilizarlo. El ser se dice de la misma manera de todo lo que es en su singularidad. El error no consiste en afirmar lo existente, sino la jerarquía entre lo que existe, que es justamente lo que parece hacer Hegel: afirmar la jerarquía de lo animal sobre lo geológico y lo vegetal. Lo animal sería la causa final de las otras formas del ser. En una escala rígida, no hay devenir posible entre las formas de vida, no hay involución posible. Si la vida animal es la verdad de la geológica y vegetal, ante ella estas son meras mentiras. El punto de inconmensurabilidad parece haber aparecido entre Hegel y Deleuze.

\footnotetext{
78 Sobre la diferencia entre regresión e involución, cf. supra.

79 Deleuze y Guattari aclaran que no comparten la consideración del animal que "retiene del animal ciertos caracteres, especies y géneros, formas y funciones, etc." (ibid., p. 292). Los que tienen necesidad de "ciertos caracteres" para ubicar a un individuo singular en el árbol de la naturaleza o de la trama social son el Estado (para clasificar a los hombres) o de la historia natural y la ciencia (para clasificar los animales mismos) (ibid.). "Nosotros no nos interesamos en los caracteres, nos interesamos en los modos de expansión, de propagación, de ocupación, de contagio, poblamiento" (ibid., pp. 292-293). Pero de ello no se sigue su rechazo o negación radical de todo lo determinado, sino la afirmación del carácter ficcional de las determinaciones. Deleuze y Guattari utilizan los contenidos de la ciencia para ocupar esos lugares, esos términos entre los cuales los devenires pasan, sin que esto implique un compromiso epistémico. Esta falta de compromiso epistémico puede extenderse a todos los contenidos científicos que utilizan con fines filosóficos. De allí que la ciencia caiga en boca del profesor Challenger. De allí la explicación de alguna de las paradojas que señalábamos al inicio. De alli la ciencia ficción. Respecto a la noción de especie, su importancia práctica en las ciencias y los diferentes criterios de clasificación, $c f$. Cuenot, L. L'éspèce, París: Doin, 1936, citado en Deleuze, Différence et répétition, p. 280 y en Deleuze, G. y F. Guattari, Mille plateaux, pp. 327-328.

80 "Devenir no es producir" (ibid., p. 292).

81 Cf. Deleuze, G., Différence et répétition, pp. 52 ss.
} 
Incluso la exposición silogística de la vida animal parece confirmar que Hegel es partidario de la jerarquía natural, de la irreversibilidad de la evolución. En efecto, el silogismo animal (S-P-U82) es presentado como la forma real (Wirkliche), donde el género, como representante de lo universal en la naturaleza, es la conclusión, el cierre (Schluss), que actúa con la fuerza de la causa final: "El género es la fuerza contra lo singular y su proceso; supera este singular y produce lo otro"83. El silogismo aparece como flecha que señala el buen sentido desde lo singular hasta lo universal, de la diferencia hasta su causa final donde está condenado a disolverse ("la razón como tendencia a la identidad, proceso

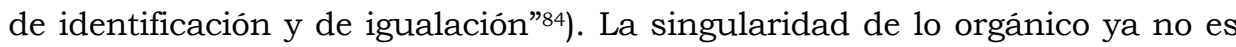
mediación ni conclusión, sino solo premisa destinada a borrarse como error. La fuerza de las singularidades y su arbitrio se reduce ante la realidad de lo universal en la forma del género. En la medida en que las formas inferiores van quedando atrás y la exposición se aproxima al supuesto patrón de medida y animal originario (el hombre) ${ }^{85}$, los desvíos y anomalías parecen reducirse. La "multiplicidad de modificaciones de su forma" que la vida habilita ${ }^{86}$, la singularidad rica de lo orgánico, es una anomalía a vencer por el trabajo del concepto.

Así, al llegar a la vida animal, la afinidad entre Hegel y la ciencia de su época parece estrecharse ("la mejor concepción de la naturaleza es lo que sea que las ciencias determinen que es el caso"). La organización en escalones de los órdenes animales, desde las formas más simples hasta la más perfecta, parece exponer el tipo universal determinado por el concepto. Cuanto más evolucionado su objeto, más certeras se vuelven las ciencias (reforzando así el contrapunto aparente con Deleuze). Hegel admira cómo en la escala de la naturaleza se observa el calco, la repetición mecánica de la estructura de su sistema. En esa medida, Hegel valora los árboles de la naturaleza que los científicos construyen en su época. Traza con pasión la evolución de los mismos, y su genealogia: Aristóteles, Lineo, Jussieu, Lamarck y Cuvier ${ }^{87}$ y su escuela. Destaca con entusiasmo los "grandes avances de la zoología y la anatomía comparada"88. Las especies no son más que la particularización del

82 "Lo orgánico está mediado con el género a través de lo inorgánico (S-P-U)" (Hegel, G.W.F., Enzyklopädie, Werke in zwanzig Bänden, v. IX, p. 370).

${ }^{83}$ Ibid.

${ }^{84}$ Deleuze, G., Différence et répétition, p. 288.

85 "[El hombre es] el patrón de medida y el animal originario [Urtier]" (Hegel, G.W.F., Enzyklopädie, Werke in zwanzig Bänden, v. IX, p. 504).

${ }_{86}^{86}$ Ibid., p. 502.

${ }^{87}$ Cf. ibid., pp. 508-509.

${ }^{88}$ Ibid., p. 500 [423]. 
género, exponiendo armoniosamente en forma de escalones de desarrollo de la naturaleza las determinaciones universales del concepto. Las tuercas de los borceguíes españoles se cierran: "El género se particulariza primeramente en especies en general. Las distintas figuraciones y órdenes de los animales tienen en su base el modelo [Typus] universal de animal determinado por el concepto, que la naturaleza expone [darstellt] en parte en los escalones del desarrollo de la naturaleza, desde la organización más simple hasta la más perfecta, en la cual la naturaleza es un instrumento del espíritu"89.

Sin embargo, la organización como escala de la naturaleza se ve constantemente contrariada. La naturaleza, lejos de contar con ventanas allí donde se requiere en virtud de la armonía, muestra constantemente anomalias y desviaciones. ¿Cómo es posible si lo universal aparece en el género como la fuerza que arrasa con las singularidades? Quizás se trate de un defecto de la anatomía comparada, que su progreso como ciencia debería ir subsanando paulatinamente. Quizás, como acusaría Tarde, Hegel no hace sino fabricar vivientes alli donde la ciencia natural no provee los elementos que respeten la simetría buscada entre espíritu y naturaleza, “¿cómo se hacen en arquitectura falsas ventanas, para completar los marcos de sus triadas?"90. Pero el problema es mucho más profundo: "El concepto existe en la vida no en cuanto tal; somete, por tanto, su existencia a las múltiples condiciones y circunstancias de la naturaleza exterior y puede aparecer en las formas más pobres; la fecundidad de la tierra hace brotar vida por todas partes y de todas las maneras. El mundo animal, casi menos aun que las otras esferas de la naturaleza, puede exponer un sistema independiente y racional de organización, asirse a las formas que fueran determinadas por el concepto y preservarlas de mezclas, atrofias y formas intermedias frente a la imperfección y mescolanza de los condicionamientos. Esta debilidad del concepto en la naturaleza en general no solamente somete la formación de los individuos a azares extrínsecos -el animal desarrollado (y el ser humano sobre todo) está expuesto a deformaciones monstruosas-, sino que también los géneros se encuentran enteramente sometidos a las modificaciones de la vida universal exterior de la naturaleza, cuyo cambio el animal comparte y atraviesa" ${ }^{11}$.

\footnotetext{
89 Ibid., p. 500 [423, trad. modificada]. El subrayado de "en parte" es nuestro.

90 Tarde, G., L'opposition universelle, Paris: Alcan, 1897, p. 78. Tomo la cita del relevo de la relación entre Deleuze y Tarde realizado por Markman, A. y C. Cabrera, "Diferencia y repetición en Gabriel de Tarde", en Ferreyra, J. y M. Soich (eds.), Gilles Deleuze y las fuentes de su filosofía, Buenos Aires: La Almohada, 2014, pp. 59-77.

91 Hegel, G.W.F., Enzyklopädie, Werke in zwanzig Bänden, v. IX, pp. 501-502 [425].
} 
Es la propia esencia del concepto la que hace que no pueda existir como tal, plenamente, en la naturaleza. Lo propio de la naturaleza es sustraerse a él, alienarse. No es una mera falta de los animales efectivamente existentes no adecuarse al concepto -como Hegel por momentos sugiere ${ }^{92}-$, sino la expresión de su carácter a-conceptual, en tanto "conceptos naturales" (géneros). Los desvios, las imperfecciones, los monstruos y las aberraciones son la marca de esa alienación, de ese no-ser-conceptual de la naturaleza. La ciencia, como consecuencia necesaria, nunca será exacta. Por mucho que evolucione nunca podrá construir un cuadro de la naturaleza que comprenda efectivamente todos los seres vivientes que existen en el mundo, porque el cambio atraviesa enteramente el reino animal. La ciencia explica lo que es en la naturaleza, pero esta forma de ser repugna al concepto, le es absolutamente extraño. Esto explicaría en parte la letra de Hegel. Pero no es la última palabra de su espíritu.

\section{El concepto de la naturaleza: Hegel con Deleuze}

"This shimmering space, where imagination and reality intersect this is the place this is where we live"

Nick Cave

Una interpretación de la naturaleza como mera alienación del concepto, carente por lo tanto de todo concepto propio, cerrada sobre sí misma y alienada del pulso viviente y dinámico del silogismo de lo real, solo puede sostenerse mediante una lectura sesgada y parcial de la letra hegeliana. El trabajo del concepto es mucho más ambicioso que su mera repetición mecánica en lo empírico, y el rol de la singularidad es mucho más fundamental que el simple hecho de desvanecerse. Las anomalías y desviaciones no son solo la expresión de la impotencia del concepto en la naturaleza, o del ser-no-conceptual de la misma. Hay algo verdadero en los monstruos y las aberraciones. Hay algo insuficiente que debe ser superado en la postulación de un bucólico cuadro de la naturaleza "sin las perturbaciones características de lo que nos es contemporáneo"93.

\footnotetext{
92 "La infinitud de formas de lo animal no debe ser tomado como si la necesidad de ordenes fue absolutamente fija. Al contrario, se debe tomar las determinaciones universales como regla y comparar con ella las formas naturales... Estas [formas naturales] deben medirse con aquella [regla universal] y en tanto esta realidad no se corresponde [con aquella regla], es su falta" (ibid., p. 503).

${ }_{93}$ Cf. Foucault, M., Las palabras y las cosas, Frost, E. (trad.), Buenos Aires, Siglo XXI, 1968.
} 
En efecto, cuando Hegel dice que "la naturaleza expone el modelo universal de animal determinado por el concepto a través de los escalones de su desarrollo"94, dice también que lo hace solo en parte. Solo en parte. Limitarse a esa parte es reprimir la otra, la cual justamente hace problemática la simple adscripción de Hegel al modelo heredado de la scala naturae.

¿Cuál es la otra parte en la cual también la naturaleza expone el universal? Son "las distintas circunstancias y condiciones de la naturaleza de los elementos"95. Si las circunstancias y las condiciones también exponen el universal, entonces no se limitan a dar cuenta de una naturaleza testaruda que resiste a un concepto impotente. También exponen algo que remite a las determinaciones propias del concepto. Este segundo lado de la Darstellung del concepto parece contradecir la naturaleza del concepto en tanto árbol ideal de la naturaleza. Parece también contradecir el rol que tiene el azar de explicar la falla de la empiria de ajustarse al concepto "en tanto tal". ¿Cómo podrían las circunstancias y condiciones limitarse a explicar las fallas del concepto y al mismo tiempo expresar determinaciones que le son propias? ¿Cómo podría la expresión del concepto como "escalones de desarrollo" ser su esencia en tanto escala ideal y al mismo tiempo solo un lado de su expresión total?

Estas contradicciones son solo aparentes, fruto de una imagen distorsionada por una lectura unilateral del funcionamiento del sistema en Hegel. Las reducciones necesarias para agrupar a los animales en géneros y especies -y a estos en escalones- destruyen algo esencial del trabajo del concepto, que no puede quedar atrapado por una grilla que le impone caminos necesarios y abismos infranqueables, limites hasta donde su acción no puede llegar, transformaciones imposibles. Es la pobreza de lo humano su atraparse en sus propias divisiones. "Solo el entendimiento puede realizar estas diferenciaciones fijas"96, y el concepto no se confunde con el entendimiento. Por el contrario, las formas más elevadas del espíritu implican un devenir, un vacilar de las determinaciones del entendimiento. Hegel no se pone sin resquebrajarlos los borceguíes españoles que los avances de la zoología y la anatomía comparada le proporcionan, y de hecho cita el pasaje del Fausto para apuntalar su crítica a la concepción científica del conocimiento como un esqueleto muerto que atrapa partes dispersas que dependen del encheiresin naturae alquímico para entrar en relación. Los géneros se encuentran enteramente sometidos a las modificaciones

${ }^{94}$ Hegel, G.W.F., Enzyklopädie, Werke in zwanzig Bänden, v. IX, p. 500 [423]. Cf. supra.

95 Ibid.

${ }^{96}$ Ibid., p. 512. El subrayado es mío. 
de la vida universal: el concepto determina las distintas figuraciones y órdenes de los animales en su fijeza, pero también en su devenir, sus circunstancias y condiciones. Lejos de ser impotencia, en su devenir, sus anomalias y sus monstruosidades la naturaleza también realiza el espíritu.

Entre los diferentes miembros del silogismo de silogismos (Idea, Naturaleza, Espíritu) $)^{97}$ no puede haber ni una lógica absolutamente idéntica, ni una escisión radical que los haga absolutamente ajenos (alienados entre sí). Entre los tres miembros fundamentales hay simetrias, pero también desfases, y estos últimos son lo que mantiene viviente al sistema. La Idea, el universal concreto, no solo construye el árbol de la naturaleza, sino que también pasa entre sus mallas, sin conducir su forma y estructura, sin definir las líneas entre los géneros, sino, por el contrario, vivificándolos: haciéndolos ser singulares. La singularidad de lo orgánico no está solo condenada a desaparecer98: si así fuera, no tendría sentido que Hegel coloque a la Naturaleza como conclusión del tercer silogismo del silogismo de silogismos ("la idea de la filosofia"), en tanto "proceso de la idea que está-siendo en sí objetivamente" 99 . Hay una verdad específica de la singularidad que la naturaleza como aparente rapsodia de diferencias expresa. A esa verdad, inherente al sistema hegeliano, Deleuze le ha dado cauce preponderante en su obra ${ }^{100}$.

\footnotetext{
${ }^{97}$ Cf. Hegel, G.W.F., Enzyklopädie, Werke in zwanzig Bänden, v. IX, pp. $393-394$ [603-604]. Cf. supra, nota 17.

${ }_{98}$ Lo cual no quiere decir que lo universal desde el punto de vista de la singularidad, no constituya una amenaza de disolución. Desde el punto de vista empírico ("la muerte violenta es el destino natural de los individuos" (ibid., v. IX, p. 500 [423])), pero también trascendental. La disolución es efecto de "las modificaciones de la vida universal exterior de la naturaleza", pero estas no contrarian la actividad del concepto, ya que las "distintas circunstancias y condiciones de la naturaleza" son también Darstellung del concepto. Hay una fuerza conceptual, y por tanto trascendental que amenaza la escala natural y los géneros que la constituyen los escalones de su desarrollo, aun los más perfectos. El hombre mismo no es solo la cúspide de la naturaleza como patrón de medida y animal originario. También está condenado a borrarse en el espíritu absoluto. Vuelve a resonar la fórmula "cuerpo sin órganos = idea absoluta", ahora en un sentido terrible (para nosotros, hombres). 99 Ibid.

${ }^{100}$ La confluencia de Hegel con el espíritu deleuziano se puede observar en torno a su posiciona120 miento en la polémica que enfrentó a Cuvier y Geoffreoy Saint-Hilaire en el seno de la Academia Real de las Ciencias francesa en el mismo año de la publicación de la Enciclopedia hegeliana. En principio, todo parece encolumnarse en la visión de Hegel y Deleuze como rivales irreconciliables: mientras Hegel elogia a Cuvier, y no hace mención alguna a Saint-Hilaire, Deleuze toma decidido partido por Saint-Hilaire (respecto a la polémica entre Cuvier y Saint-Hilaire, y la recepción de la misma en Deleuze y su presencia tanto en Diferencia y repetición como en Mil mesetas, $c f$. Soich, M. "Cuatro causas para leer a Deleuze con Saint-Hilaire", en Ferreyra, J. y M. Soich (eds.), Gilles Deleuze y las fuentes de su filosofia, Buenos Aires: La Almohada, 2014, pp. 13-27). Pero esta contraposición depende de los supuestos en torno a la filosofia de la naturaleza de Hegel que hemos puesto en cuestión. Hegel apoya a Cuvier en la parte de la exposición del concepto como
} 
En Hegel la "fuerza del género", en lugar de implicar la luz blanca cegadora de la identidad, es la instancia de sostenimiento de lo singular. Y puede serlo porque los silogismos deben pensarse en acción recíproca. El género es conclusión, causa final, pero también término medio y premisa mayor. Lo singular es premisa (ha de ser superada, ha de llegar a su conclusión que implica su superación) pero también término medio y conclusión. Los lugares que ocupan los términos en un silogismo responden a la lógica del concepto y, en el límite, al silogismo de silogismos. Si alguna prioridad, si alguna "verdad superior" tiene el silogismo animal, es la de señalar que la conclusión es lo universal. Sin universal lo singular y lo particular están condenados. Pero concluir no es clausurar, y no lo es porque el término que clausura también hace pasar (es término medio del silogismo geológico) y deja pasar (como premisa del silogismo vegetal cuya conclusión es lo singular). Juntos, los tres silogismos de lo orgánico constituyen lo conceptual de la vida, que no es en él menos fecunda y diferenciada que en Deleuze. Los tres juntos permiten a la Naturaleza cumplir acabadamente el rol de lo singular que le corresponde en el silogismo de silogismos.

El objetivo de la filosofia de la naturaleza, tanto en Hegel como en Deleuze, es tratar de pensar de qué manera, sobre el fondo de la universalidad (sea del concepto, sea del cuerpo sin órganos) es posible pensar la emergencia las formas existentes, con sus partes, estructuras y materialidad, con su singularidad y diferencia. En este proyecto, las ciencias empíricas no tienen un rol asertórico sino hipotético. Si el mundo fuera como los científicos lo encuentran, ¿de qué manera podría ser producido por una universalidad conceptual o diferencial? $¿$ ¿De qué manera esa singularidad puede concluirse con la universalidad? ¿De qué manera esos términos, esos estratos, esos árboles, pueden crecer entre lo que dejan pasar? La violencia de esa interpelación, de la cual ninguno de estos filósofos rehuye, es lo que permite a sus pensamientos el grado de complejidad, sutileza y determinación que, a lo largo del desarrollo de su obra, han logrado alcanzar. Y también encontrar su alianza profunda debajo de la aparente contraposición irreconciliable de sus perspectivas filosóficas.

escalones de desarrollo de la naturaleza, pero se acerca a Saint-Hilare cuando se resiste a las "fallas infranqueables entre tipos de animales" (Cf. Deleuze, G., Différence et répétition, p. 278). En ese sentido, Hegel afirma que la base es "un modelo universal de animal" (Hegel, G.W.F., Enzyklopädie, Werke in zwanzig Bänden, v. X, p. 500 [423]) mientras Saint-Hilaire sostiene que "ya no existen animales diversos. Un hecho único los domina, el que aparece es como un único ser. Él es, reside en la Animalidad; ser abstracto, tangible a través de nuestros sentidos bajo figuras diversas" (Saint-Hilaire, E. Principios de filosofía zoológica, Ires, P. (trad.) Buenos Aires: Cactus, 2009, pp. 27-28). 


\section{Bibliografia}

Adorno, T. Metaphysik, Begriff und Probleme, Fráncfort d.M.: Suhrkamp, 1998.

Cabrera, C. y A. Markman, "Diferencia y repetición en Gabriel de Tarde", en Ferreyra, J. y M. Soich (eds.), Gilles Deleuze y las fuentes de su filosofia, Buenos Aires: La Almohada, 2014, pp. 59-77.

Colebrook, C., Deleuze and the Meaning of Life, Nueva York, Continuum, 2010. https:// doi.org/10.5040/9781472546289

Cragnolini, M., Moradas nietzscheanas. Del símismo, del otro y del "entre”, Buenos Aires: Ediciones La Cebra, 2006.

Cuenot, L., L'éspèce, París: Doin, 1936.

Deleuze, G., Différence et répétition, París: PUF, 1968.

Deleuze, G. y F. Guattari, Qu'est-ce que la philosophie?, París: Minuit, 1991.

Deleuze, G. y F. Guattari, Mille Plateaux, París: Minuit, 1980.

Ferreyra, J., "El problema del comienzo en Hegel y Deleuze", VIII Jornadas de Investigación en Filosofia, La Plata: 27 al 29 de abril de 2011, http:/ / www.memoria.fahce.unlp. edu.ar/trab_eventos/ev.1281/ev.1281.pdf (última consulta 6 de junio de 2016).

Ferreyra, J., "Deleuze y el Estado", en: Deus Mortalis, N 10, 2011-2012.

Fichte, J., Sobre el concepto de la doctrina de la ciencia, Navarro, B. (trad.), México : Centro de Estudios Filosóficos, 1963.

Foucault, M. Las palabras y las cosas, Frost, E. (trad.), Buenos Aires: Siglo XXI, 1968. Goethe, J.W. Fausto, Roviralta Borrell, J. (trad.), Buenos Aires: Losada, 2005.

Gualandi, A., Deleuze, París: Les Belles Lettres, 1998.

Hardt, M., Gilles Deleuze, an Apprenticeship in Philosophy, Mineápolis: University of Minnesota Press, 1993.

Hegel, G.W.F. Enzyklopädie Werke in zwanzig Bänden, Moldenhauer, E. y K.M. Michel (eds.). Fráncfort d.M.: Suhrkamp, v. VIII-X, 1970f.

Hegel, G.W.F. Enciclopedia de las ciencias filosóficas, Valls Plana, R. (trad.), Madrid: Alianza Editorial, 1997.

Houle, K. y J. Vernon (eds.) Hegel and Deleuze, Together Again for the First Time, Evanston: Nothwestern University Press, 2013.

Houlgate, S., "Reason in Nature", en: An Introducton to Hegel, Malden: Blackwell, 2005.

Kant, I. Crítica de la razón pura, Caimi, M. (trad.), Buenos Aires: Colihue, 2009.

Le Brazic, D., "Hélène Machinal. Conan Doyle: de Sherlock Holmes au Professeur Challenger", en: Journal of the Short Story in English, 48 (2007), http://jsse. revues.org/782, última consulta el 5 de diciembre de 2014.

122 Novalis, L'encyclopédie, Wasmuth, E. (trad.), París: Minuit, 1966.

Petry, M.J., Hegel's Philosophy of Nature, Londres: Allen and Unwin, 1970.

Pinkard, T., Hegel's Naturalism, Mind, Nature and the Final Ends of Life, Nueva York: Oxford University Press, 2012. https://doi.org/10.1093/acprof: oso/9780199860791.001.0001

Popper, K., La sociedad abierta y sus enemigos, Loedel, E. (trad.), Madrid: Paidós, 2006.

Saint-Hilaire, E. Principios de filosofía zoológica, Ires, P. (trad.), Cactus, Buenos Aires, 2009. 
Scheler, M., El puesto del hombre en el cosmos, Gaos, J. (trad.), Buenos Aires: Losada, 1938.

Schelling, F.W.J., System des transzendentales Idealismus, Hamburgo: Meiner, 1957.

Simondon, G., L'individuation, à la lumiére des notions de forme et d'information, París: Millon, 2005.

Soich, M. "Cuatro causas para leer a Deleuze con Saint-Hilaire”, en: J. Ferreyra y M. Soich (eds.), Gilles Deleuze y las fuentes de su filosofia, Buenos Aires: La Almohada, 2014, pp. 13-27.

Sokal, A., Impostures intellectuelles, Paris: Odile Jacob, 1997.

Somers-Hall, H., Hegel, Deleuze, and the Critique of Representation: Dialectics of Negation and Difference, Albany: SUNY Press, 2012.

Stone, A., Petrified Intelligence, Nature in Hegel's Philosophy, Nueva York: SUNY, 2005.

Tarde, G., L'opposition universelle, París: Alcan, 1897.

Vialleton, L., Membres et ceintures des vertébrés tétrapodes, París: Doin, 1924.

Recibido: 12/01/2015

Aceptado: 20/04/2016 